\title{
Utilization of the modified WHO partograph in assessing the progress of labour in a metropolitan area in Ghana
}

\author{
Baafuor K. Opoku ${ }^{1,2^{*}}$ and Samuel Blay Nguah ${ }^{3}$ \\ *Correspondence: baafuoropoku@yahoo.com

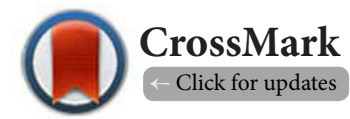

'Department of Obstetrics and Gynaecology, Kwame Nkrumah University of Science and Technology, Kumasi, Ghana. ${ }^{2}$ Department of Obstetrics and Gynaecology, Komfo Anokye Teaching Hospital, Kumasi, Ghana.

${ }^{3}$ Department of Child Health, Komfo Anokye Teaching Hospital, Kumasi, Ghana.

\begin{abstract}
Maternal mortality ratio averages 230 per 100,000 live births in developing countries. Obstructed labour, which is a major cause results from prolonged, neglected labour. The partograph as recommended by the World Health Organization is a graphical tool used to monitor the progress of the first stage of labour, thereby preventing prolonged labour. The partograph has been in use in Ghana since 1989. The study was conducted to ascertain the proportion and correct use of the partograph in monitoring labours in 4 hospitals in a metropolitan area of Ghana. Partograph use for labour monitoring averaged $54 \%$ in this study. Midwives formed $90 \%$ of birth attendants. For the progress of labour, parameters were monitored to standard in $55-60 \%$ of cases. Parameters pertaining to fetal well being were correctly monitored in $30-50 \%$. Maternal well being was monitored to standard in $40 \%$ of cases. Apgar scores at 1 and 5 minutes did not differ whether parameters were recorded to standard or not. We conclude from our study that almost half of labour cases were not monitored with the partograph. In those that were monitored with the partograph monitoring to standard was done in $40-60 \%$. Birth attendants either lack the skill in charting the partograph to standard protocols or do not appreciate the use of the partograph in monitoring the progress of labour. In resourcelimited centres in the developing world the use of the partograph to monitor the progress of labour cannot be overemphasized. Skilled attendants at deliveries must therefore be given regular updates on the proper use of the partograph during labours.
\end{abstract}

Keywords: Developing countries, partograph, labour, standard recording

\section{Introduction}

Approximately 300,000 maternal deaths occurred globally in 2013 , of which $98 \%$ occurred in the developing countries. On the average 230 women die per every 100,000 live births every year in developing countries [1]. Obstructed labour is one major cause of maternal mortality and usually results from neglected prolonged labour. Prolonged labour may also lead to atonic postpartum haemorrhage, maternal exhaustion and dehydration, uterine rupture and obstetric fistulas. The partograph as a graphic assessment is recommended for routine monitoring of the $1^{\text {st }}$ stage of labour to help the birth attendant identify slow progress of labour and prevent prolonged labour and its complications.

Originally called the Friedman's curve, the partograph was designed by Friedman in 1954 following a study on a large number of parturients in the USA [2]. It was further improved by Philpott and Castle who introduced the alert and action lines to facilitate interventions during labour [3]. Since then several types of partographs have been developed in various countries to suit local needs [4-6]. It is an inexpensive tool designed to provide a continuous pictorial overview of labour and has been shown to improve outcomes when used to monitor and manage labour [3]. The composite partograph was evaluated in a multicenter trial that involved 35,484 women [7]. The results showed that using the partograph reduced prolonged labour by about half (from $6.4 \%$ to $3.4 \%$ of labours) and the proportion of labours requiring augmentation from $20.7 \%$ to $9.1 \%$. Emergency caesarean sections also reduced from $9.9 \%$ to $8.3 \%$ and intrapartum stillbirths from $0.5 \%$ to $0.3 \%$. The modified WHO partograph currently being used was introduced in 2000. 
It does not have a latent phase and the active phase starts at $4.0 \mathrm{~cm}$ cervical dilatation (Figure 1). While the composite partograph was introduced in Ghana in 1989 as part of the Safe Motherhood Initiative's Life Saving Skills, the modified WHO partograph was introduced a couple of years later. It has since been used to monitor labours in health facilities in the country. Very few studies have since been conducted on its use and impact on labour and delivery in the country. One of such studies looked at the relationship between its use and birth outcomes in a teaching hospital [8].

The current study was conducted to assess the proportion of labours which is monitored by use of the partograph and also find out their proper completion for women in labour in public health institutions in Kumasi, Ghana. Kumasi is the second largest city in Ghana with a population of 2.05 million people [9] and covering an area of $254 \mathrm{~km}^{2}$. There are 5 public hospitals, one university hospital, one teaching hospital and about 200 other health facilities (mission, quasi-government and private hospitals, clinics and maternity homes) in the city [10]. The study is designed to find out the proportion of women whose labours are monitored by the partograph, and whether monitoring is done according to standard protocols for use of the partograph. Answers to these questions will be important to inform policies and strategies in the provision of maternity care services in the country, especially in the areas of preventing prolonged labour and its attendant complications.

\section{Methods}

A descriptive study based on retrospective document study was used to review the completion of partographs that have been used to monitor labours in selected health facilities in the metropolis. It was conducted over a 3-month period in 4 of the hospitals sampled from public hospitals within the metropolis. The participating facilities sampled were Komfo Anokye Teaching Hospital, Manhyia, Suntreso and Kumasi South District hospitals.

Partographs that were reviewed included those that had complete or partially complete information in them. Partographs that were excluded were those that had no entries at all, had only a delivery summary or had to be abandoned due to a developed complication that needed urgent operative delivery.

All women who delivered in these hospitals during the period under study had their partograph sheets retrieved from their in-patient folders within 24 hours of delivery. All information that was needed, as outlined in a questionnaire were extracted from the sheets and entered into EpiData V3.1 database [11].

\section{Sampling method}

The sample size was determined using a single proportion formula of $n=z^{2} p(1-p) / w^{2}$, where $n$ is the required sample size, $z$ is the standard normal deviate set at 1.96 (for $95 \%$ confidence level), $w$ is the desired degree of accuracy (taken as 0.05) and $p$ is the estimate of the proportion of partographs on which all components are recorded up to standard (estimated to be $40 \%$ in this study). This gave a sample size of 380 partographs. Because of multi-stage sampling, a factor of 2.0 was added giving a final sample size of 760 which was evenly distributed to the participating facilities.

The components of the partograph were assessed to determine whether they had been monitored according to standard protocol [12].

Standard protocols as defined here include

1. Fetal heart rate, maternal pulse and uterine contractions monitored and charted every 30 minutes.

2. Cervical dilatation, descent of the presenting part and moulding monitored every four hours.

3. Blood pressure monitored every 2 hours.

4. Condition of the baby after birth (APGAR score) recorded on the sheet. A score of $\geq 7$ is considered satisfactory $[13,14]$. Records that did not meet any of the listed standards or had parts missing or inadequate for each parameter of the partograph were judged as substandard. Records were judged as not recorded if no information was documented on the parameters of the partograph or completely absent from the file. Records were judged as standard if all the criteria were met for each parameter on the partograph.

\section{Ethical clearance}

Ethical clearance for the study was obtained from the Committee on Human Research, Publications and Ethics (CHRPE) of the Kwame Nkrumah University of Science \& Technology and the Komfo Anokye Teaching Hospital.

\section{Data analysis}

Data was double entered, compared and cleaned of wrongful entries. It was then exported to Stata SE 12.1 for analysis. Partograph recordings were then put together and tabulated to show the frequencies of "not done", "partially done" and "fully done" recordings. The first two categories were combined to form the "Substandard" recording while the "fully done" group represented the "Standard" recordings. The relationship between the APGAR scores at first and fifth minutes and standard of partograph recording were determined first (unadjusted) using quantile regression and then adjusted for the clustering within facilities. Finally the relationship between substandard recording and the cadre performing the deliveries was determined using a chi-square test and presented as p-values. For all analysis a two sided p-value of $>0.05$ was considered statistically significant.

\section{Results}

In all, 809 partographs that had been used to monitor labours in the 4 health facilities during the period of the study were reviewed. The mean age group was 21-30 years which formed $62.4 \%$ of the patients. Nulliparous women formed $34.7 \%$ 
Opoku et al. Research Journal of Women's Health 2015,

http://www.hoajonline.com/journals/pdf/2054-9865-2-2.pdf

doi: 10.7243/2054-9865-2-2

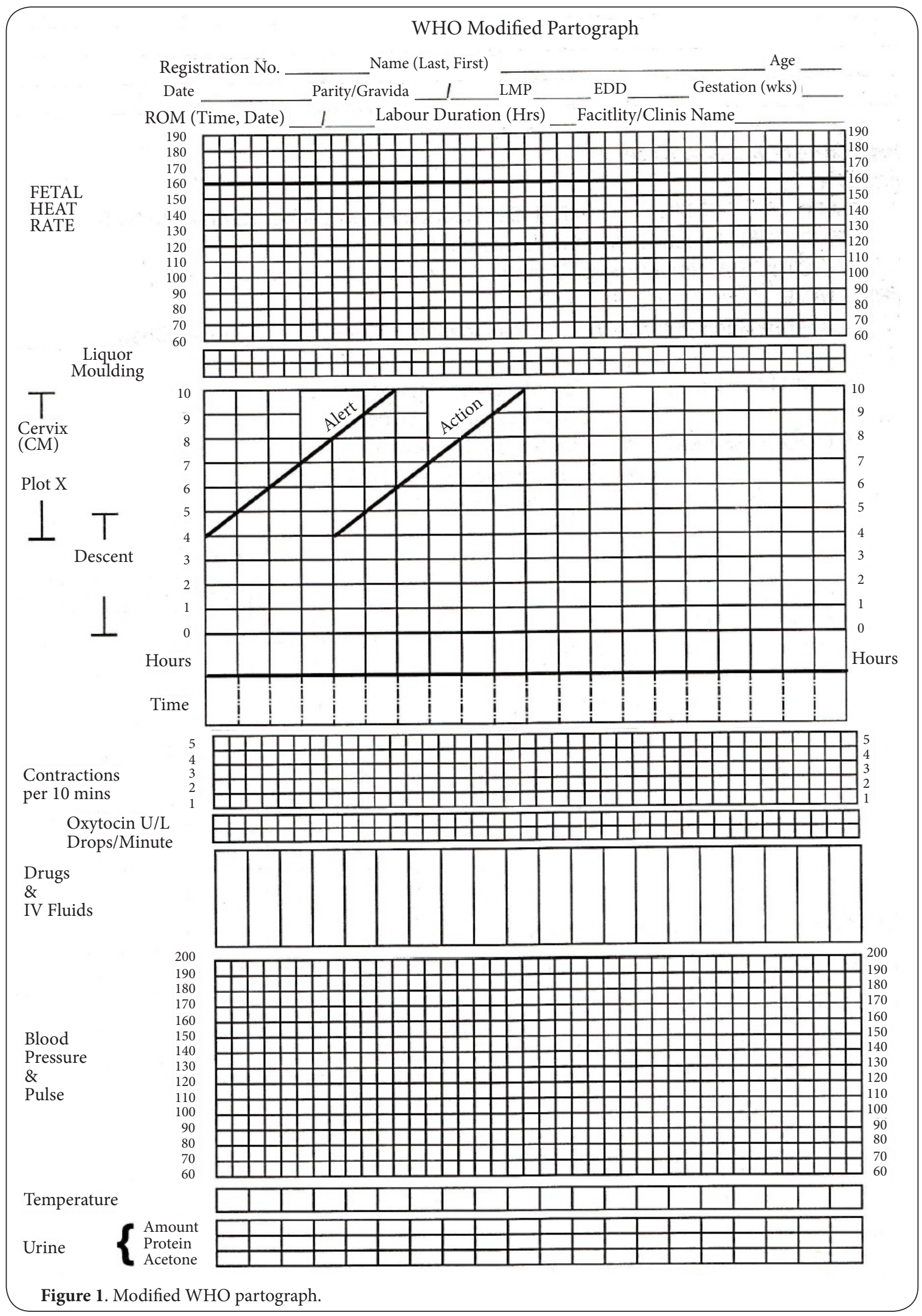


Opoku et al. Research Journal of Women's Health 2015,

while grandmultiparous women formed 3.6\%. Table 1 shows the hospitals sampled and partographs selected. Just about half of all deliveries (54.6\%) in the study were monitored with the partograph and their completion was not as expected.

Graph 1 shows standard recordings of seven parameters. The best recorded parameter was contractions $(60.2 \%)$ while the least recorded parameter was moulding (32.5\%).

Analysis showed that fetal heart rate, which is central to intrapartum monitoring of the health status of the fetus, was recorded to standard in 50\% of cases, partially recorded in $24 \%$ and not recorded at all in 25\% of cases reviewed (Table 2).

In about $44 \%$ of cases cervical dilatation was not recorded to standard. Standard recordings of contractions were done in $60 \%$ of cases. Descent was properly charted in $55 \%$ of cases and not charted at all in $25 \%$ of cases. Maternal blood pressure and pulse were properly charted in $40 \%$ of cases, just as for urine protein. In about $12 \%$ of cases APGAR scores were not recorded at all. In $12 \%$ of cases the action line of the partograph was crossed.

Table 3 shows the cadre of staff who charted the partographs. About $90 \%$ were midwives. Doctors constituted less than $2 \%$ while the rest were charted by students and auxiliary staff.

Table 1. Hospitals included in the study.

\begin{tabular}{l|lll}
\hline Name of hospital & $\begin{array}{l}\text { Proportion of deliveries } \\
\text { monitored by } \\
\text { partograph }\end{array}$ & $\begin{array}{l}\text { Partograph } \\
\text { selected }\end{array}$ \\
\cline { 2 - 4 } & \% & n & \% \\
\hline $\begin{array}{l}\text { Komfo Anokye Teaching } \\
\text { Hospital (KATH) }\end{array}$ & 50.2 & 204 & 25.2 \\
$\begin{array}{l}\text { Kumasi South Hospital } \\
\text { (KSH) }\end{array}$ & 61.5 & 200 & 24.7 \\
$\begin{array}{l}\text { Suntreso Government } \\
\text { Hospital (SGH) }\end{array}$ & 52.8 & & \\
$\begin{array}{l}\text { Manhyia District } \\
\text { Hospital (MDH) }\end{array}$ & 54.0 & 206 & 25.5 \\
Total & Average: 54.6 & 199 & 24.6 \\
\hline
\end{tabular}

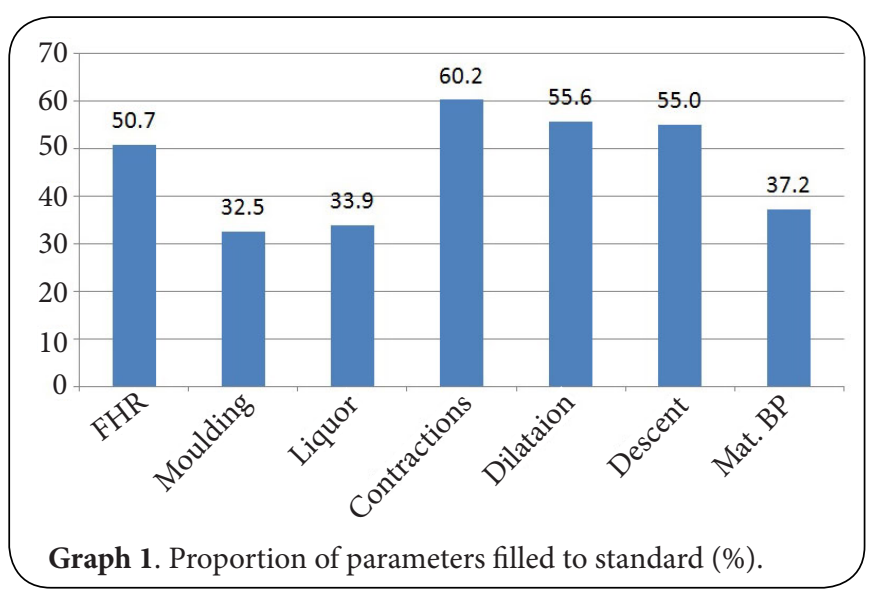

Table 2. Recordings of parameters on partographs.

\begin{tabular}{|c|c|c|}
\hline Parameter & Frequency & $\%$ \\
\hline \multicolumn{3}{|l|}{ Demographics } \\
\hline Not done & 0 & 0.0 \\
\hline Partially done & 167 & 20.6 \\
\hline Fully done & 642 & 79.4 \\
\hline \multicolumn{3}{|l|}{ Fetal heart rate } \\
\hline Not done & 206 & 25.5 \\
\hline Partially done & 193 & 23.9 \\
\hline Fully done & 410 & 50.7 \\
\hline \multicolumn{3}{|c|}{ Nature of liquor } \\
\hline Not done & 359 & 44.4 \\
\hline Partially done & 176 & 21.8 \\
\hline Fully done & 274 & 33.9 \\
\hline \multicolumn{3}{|l|}{ Moulding } \\
\hline Not done & 392 & 48.5 \\
\hline Partially done & 154 & 19.0 \\
\hline Fully done & 263 & 32.5 \\
\hline \multicolumn{3}{|c|}{ Cervical dilatation } \\
\hline Not done & 190 & 23.5 \\
\hline Partially done & 169 & 20.9 \\
\hline Fully done & 450 & 55.6 \\
\hline \multicolumn{3}{|l|}{ Descent } \\
\hline Not done & 201 & 24.9 \\
\hline Partially done & 163 & 20.2 \\
\hline Fully done & 445 & 55.0 \\
\hline \multicolumn{3}{|l|}{ Contractions } \\
\hline Not done & 182 & 22.5 \\
\hline Partially done & 140 & 17.3 \\
\hline Fully done & 487 & 60.2 \\
\hline \multicolumn{3}{|c|}{ Maternal BP \& Pulse } \\
\hline Not done & 198 & 24.5 \\
\hline Partially done & 287 & 35.5 \\
\hline Fully done & 324 & 40.0 \\
\hline \multicolumn{3}{|c|}{ Urine for protein } \\
\hline Not done & 282 & 34.9 \\
\hline Partially done & 204 & 25.2 \\
\hline Fully done & 323 & 39.9 \\
\hline \multicolumn{3}{|c|}{ APGAR recorded } \\
\hline No & 98 & 12.1 \\
\hline Yes & 711 & 87.9 \\
\hline \multicolumn{3}{|c|}{ Action line crossed } \\
\hline No & 694 & 88.1 \\
\hline yes & 94 & 11.9 \\
\hline
\end{tabular}

Table 4 shows the relationship between Apgar scoring and standard/substandard recordings of 5 parameters. Apgar score recordings at both 1-minute and 5-minutes did not 
Table 3. Cadre of health worker charting partograph.

\begin{tabular}{lll}
\hline Health worker cadre & $\mathbf{n}$ & $\mathbf{\%}$ \\
\hline Midwife & 725 & 89.6 \\
Doctor & 15 & 1.8 \\
Student nurse/Midwife & 22 & 2.7 \\
Unclassified & 45 & 5.5 \\
Total & 809 & 100 \\
\hline
\end{tabular}

differ whether these parameters were recorded to standard or sub-standard. For sub-standard recordings pertaining to contractions, cervical dilatations and descent, the cadre of staff charting the parameters did not make a difference Table 5. Oxytocin was used to augment labour in $36.3 \%$ of cases.

\section{Discussion}

Compared to studies on the use of the partograph done in other settings $[10,15-18]$, completion to standard (as defined earlier) in this study is relatively better, although not acceptable. The various labour parameters were recorded to standard in $32.5 \%-79.4 \%$ of cases, with the least standard recording in moulding of fetal skull and the highest in maternal demographics. It is possible that midwives, who formed the bulk of birth attendants in the study either have less skill in determining moulding or placed less emphasis on its importance in the progress of labour. For parameters pertaining to the progress of labour (contractions, cervical dilatation and descent) recording to standard occurred in $55-60 \%$ of cases in this study. This figure is higher than was found in an earlier study in Accra [8] where only $25.6 \%$ were recorded to standard. Sub-standard recordings pertaining to parameters of the progress of labour did not differ statistically among the cadre of birth attendants charting the partographs $(0.005<p<0.018)$. In an Ethiopian study cervical dilatation, uterine contractions and descent were recorded to standard in $32 \%, 21 \%$ and $6.9 \%$ respectively [17]. In at least $40 \%$ of cases in this study, abnormal/slow progress could not have been identified since parameters pertaining to the progress of labour were not recorded to standard. This indicates a lack of understanding of what the partograph is designed for-a tool to monitor the progress of labour.

Of the parameters pertaining to fetal well being (heart rate, moulding and nature of liquor), fetal heart rate was recorded to standard in about half of cases. The other parameters were recorded to standard in only about a third of cases. Again, fetal heart rate was recorded to standard in a higher proportion of cases in this study than in studies done in Ethiopia and Uganda $[17,18]$. The ability to pick up abnormal fetal heart tracings is crucial to diagnosing fetal distress in labour. In

Table 4. Relationship between substandard recordings and APGAR Scores.

\begin{tabular}{lllllll}
\hline & \multicolumn{2}{l}{ 1-min APGAR median (iqr) } & \multicolumn{2}{c}{ Unadjusted } & \multicolumn{2}{c}{ Adjusted } \\
& Substandard & Standard & Diff (95\% CI) & p-value & Diff (95\% CI) & p-value \\
\hline Fetal heart rate & $7(7-8)$ & $8(7-8)$ & $-1(-1.4$ to -0.7$)$ & $<0.001$ & $0(-0.2-0.2)$ & 1.000 \\
Contractions & $8(7-8)$ & $7(6-8)$ & $1(0.6-1.4)$ & $<0.001$ & $0(-0.2-0.2)$ & 1.000 \\
Cervical dilatation & $8(7-8)$ & $7(6-8)$ & $1(0.8-1.2)$ & $<0.001$ & $0(-0.2-0.2)$ & 1.000 \\
Descent & $8(7-8)$ & $7(6-8)$ & $1(0.8-1.2)$ & $<0.001$ & $0(-0.2-0.2)$ & 1.000 \\
BP \& Pulse & $8(7-8)$ & $7(6-8)$ & $1(0.7-1.3)$ & $<0.001$ & $0(-0.2-0.2)$ & 1.000 \\
\hline & 5 -min APGAR median (iqr) & \multicolumn{2}{c}{ Unadjusted } & \multicolumn{2}{c}{ Adjusted } \\
& Substandard & Standard & Diff (95\% CI) & p-value & Diff (95\% CI) p-value \\
\hline Fetal heart rate & $9(8-9)$ & $9(8-9)$ & $0(-0.2-0.2)$ & 1.000 & $0(-0.2-0.2)$ & 1.000 \\
Contractions & $9(8-9)$ & $9(8-9)$ & $0(-0.2-0.2)$ & 1.000 & $0(-0.2-0.2)$ & 1.000 \\
Cervical dilatation & $9(8-9)$ & $9(8-9)$ & $0(-0.2-0.2)$ & 1.000 & $0(-0.2-0.2)$ & 1.000 \\
Descent & $9(8-9)$ & $9(8-9)$ & $0(-0.2-0.2)$ & 1.000 & $0(-0.2-0.2)$ & 1.000 \\
BP \& Pulse & $9(8-9)$ & $9(8-9)$ & $0(-0.1-0.1)$ & 1.000 & $0(-0.2-0.2)$ & 1.000 \\
\hline
\end{tabular}

Table 5. Relation between cadre of staff and substandard recordings.

\begin{tabular}{lllllll}
\hline \multicolumn{7}{c}{ Cadre $\mathbf{n}(\%)$} \\
\hline Sub-standard recording & Midwife $(\mathbf{n}=\mathbf{7 2 5})$ & Doctor $(\mathbf{n = 1 5 )}$ & Student $(\mathbf{n = 2 2})$ & Unknown $(\mathbf{n}=\mathbf{4 5})$ & Total (n=809) & $\mathbf{p}$-value \\
\hline Fetal heart rate & $352(48.6)$ & $6(40)$ & $11(50)$ & $30(63.8)$ & $399(49.3)$ & 0.198 \\
Contractions & $282(38.9)$ & $2(13.3)$ & $10(45.5)$ & $28(59.6)$ & $322(39.8)$ & 0.005 \\
Cervical dilatations & $323(44.6)$ & $4(26.7)$ & $5(22.7)$ & $27(57.5)$ & $359(44.4)$ & 0.025 \\
Descent & $325(44.8)$ & $4(26.7)$ & $6(27.3)$ & $29(61.7)$ & $364(45)$ & 0.018 \\
BP \& Pulse & $454(62.6)$ & $9(60)$ & $13(59.1)$ & $32(68.1)$ & $508(62.8)$ & 0.872 \\
\hline
\end{tabular}


low-resource settings where continuous electronic fetal heart monitoring is not universally available, proper charting of fetal heart rates on the partograph is key to identifying fetal heart rate abnormalities and the early stages of fetal distress.

Parameters pertaining to maternal well being (blood pressure, pulse and nature of urine) were recorded to standard in about $40 \%$ of cases. It is known that blood pressure during the $1^{\text {st }}$ stage of labour is influenced by the physiological effects of labour itself and the use of drugs such as oxytocin and epidural analgesia [19]. Oxytocin was used to augment labour in $36 \%$ of cases in this study. This figure may not be a true reflection of those who might have needed augmentation since parameters pertaining to the progress of labour were not recorded to standard in $40 \%$ of cases. The effects of oxytocin on blood pressure could not have been ascertained in up to $60 \%$ of patients because their blood pressures were not recorded to standard.

Neonatal outcomes in terms of Apgar scores at both 1-minute and at 5-minutes did not differ statistically in this study whether parameters were recorded to standard or were substandard. The WHO expects the partograph to be used in all births attended to by skilled birth attendants in developing countries. The proportion of deliveries attended to by skilled birth attendants have steadily increased in the country from 40\% in 1988 to $68 \%$ in 2011 [20,21]. However, partograph use in this study was $54 \%$, a figure that is below the national figure of deliveries conducted by skilled attendants. Regular in-service training for skilled birth attendants has to be undertaken to enhance their understanding and capabilities in using the partograph to monitor the progress of labour in the country. There is the need to ensure that birth attendants see proper completion of the partograph as necessary for proper labour management. A supportive system of peers and supervisors will ensure proper use of the partograph.

A limitation of this study is that it assessed only the completion of the parameters of the partograph during labour and not whether partograph completion was translated into labour management. Completion may not necessarily mean use and the findings of the present study may not show the extent of use of the partograph for monitoring the progress of labour in the health facilities. Partographs may have been used only to record events in labour rather than to guide actual management of labour.

Neonatal outcomes in terms of Apgar scores at 1 and 5 -minutes did not differ statistically whether parameters were recorded to standard or substandard. The authors cannot comment whether this is incidental or related to the ability of attending staff to properly assign scores to the parameters in Apgar scoring. Further, the reasons why more than half of labours were not monitored by the partograph was also not answered in this study.

\section{Conclusion}

Almost 26 years after its introduction in the country, it is evident that birth attendants need more education on the importance and correct usage of the partograph to ensure that all labours are monitored with the partograph. Health workers must also be taught to record parameters according to standard protocols as appropriate completion of the partograph is key to detecting abnormal progress of labour. Early detection and timely intervention of obstetric complications are the most important activities to prevent maternal and perinatal mortality and morbidity.

Training and re-training of birth attendants, especially mid wives (as they form the bulk of health attendants at delivery) need to be done to ensure proper understanding of the partograph as a tool for labour monitoring and management.

\section{Competing interests}

The authors declare that they have no competing interests.

\section{Authors' contributions}

\begin{tabular}{|l|c|c|}
\hline Authors' contributions & BKO & SBN \\
\hline Research concept and design & $\checkmark$ & -- \\
\hline Collection and/or assembly of data & $\checkmark$ & -- \\
\hline Data analysis and interpretation & -- & $\checkmark$ \\
\hline Writing the article & $\checkmark$ & $\checkmark$ \\
\hline Critical revision of the article & -- & -- \\
\hline Final approval of article & $\checkmark$ & $\checkmark$ \\
\hline Statistical analysis & -- & -- \\
\hline
\end{tabular}

\section{Acknowledgement}

We acknowledge the invaluable contributions of the staff of the labour wards of the hospitals involved. We thank Jonathan, Emmanuel, Nana Yaw and Cecilia who were the data collectors. We also thank Miss Hannah Kyerewaa Asiamah for doubly entering all data for the study.

\section{Publication history}

Editor: Erich Cosmi, University of Padua, Italy.

Received: 20-Feb-2015 Final Revised: 23-Apr-2015

Accepted: 24-Apr-2015 Published: 02-May-2015

\section{References}

1. Trends in maternal mortality ratios: 1990-2013. Estimates by WHO, UNICEF, UNFPA, World Bank and UN Population Division. 2014.

2. Friedman EA. Primigravid labor; a graphicostatistical analysis. Obstet Gynecol. 1955; 6:567-89. | Article | PubMed

3. Levin $\mathrm{K}$ and Kabagema JD A. Use of the partograph: effectiveness, training, modifications, and barriers-a literature review. New York: Engender Health/Fistula Care. 2011. | Pdf

4. O'Driscoll $\mathrm{K}$ and Stronge JM. Active management of labor. Br Med J. 1973; 3:590. | Article | PubMed Abstract | PubMed Full Text

5. Duignan NM, Studd JW and Hughes AO. Characteristics of normal labour in different racial groups. Br J Obstet Gynaecol. 1975; 82:593-601. | Article | PubMed

6. Melmed $\mathrm{H}$ and Evans $\mathrm{M}$. Predictive value of cervical dilatation rates. I. Primipara labor. Obstet Gynecol. 1976; 47:511-5. | Article | PubMed

7. WHO Partograph in management of labour. WHO Maternal Health and Safe Motherhood Programme. Lancet. 1994; 343:1399-404.

8. Gans-Lartey F, O'Brien BA, Gyekye FO and Schopflocher D. The relationship between the use of the partograph and birth outcomes 
Opoku et al. Research Journal of Women's Health 2015,

http://www.hoajonline.com/journals/pdf/2054-9865-2-2.pdf

at Korle-Bu teaching hospital. Midwifery. 2013; 29:461-7. | Article | PubMed

9. Ghana Statistical Service. 2010 Population and Housing Census. 2012. | Pdf

10. Kumasi, Ghana Health Service. Ashanti Region Annual Report. 2006.

11. Lauritsen JM and Bruus M. EpiData. A comprehensive tool for validated entry and documentation of data. The EpiData Association, Odense Denmark. 2004.

12. Nyamtema AS, Urassa DP, Massawe $S$, Massawe $A$, Lindmark $G$ and van Roosmalen J. Partogram use in the Dar es Salaam perinatal care study. Int J Gynaecol Obstet. 2008; 100:37-40. | Article | PubMed

13. Apgar V. A proposal for a new method of evaluation of the newborn infant. Curr Res Anesth Analg. 1953; 32:260-7. | Article | PubMed

14. Finster $M$ and Wood $M$. The Apgar score has survived the test of time. Anesthesiology. 2005; 102:855-7. | Article | PubMed

15. Yisma E, Dessalegn B, Astatkie A and Fesseha N. Completion of the modified World Health Organization (WHO) partograph during labour in public health institutions of Addis Ababa, Ethiopia. Reprod Health. 2013; 10:23. | Article | PubMed Abstract | PubMed Full Text

16. Orji EO and Olabode TO. Comparative study of labour progress and delivery outcome among induced versus spontaneous labour in nulliparous women using modified WHO partograph. NJOG. 2008; 3:2428. | Article

17. Yisma E, Dessalegn B, Astatkie A and Fesseha N. Knowledge and utilization of partograph among obstetric care givers in public health institutions of Addis Ababa, Ethiopia. BMC Pregnancy Childbirth. 2013; 13:17. | Article | PubMed Abstract | PubMed Full Text

18. Ogwang S, Karyabakabo Z and Rutebemberwa E. Assessment of partogram use during labour in Rujumbura Health Sub District, Rukungiri District, Uganda. Afr Health Sci. 2009; 9 Suppl 1:S27-34. PubMed Abstract | PubMed Full Text

19. Cohen J, Vaiman D, Sibai BM and Haddad B. Blood pressure changes during the first stage of labor and for the prediction of early postpartum preeclampsia: a prospective study. Eur J Obstet Gynecol Reprod Biol. 2015; 184:103-7. | Article I PubMed

20. Accra, Ghana Statistical Service (GSS), Ghana Health Service (GHS) and ICF Macro. Ghana Demographic and Health Survey. 2008.

21. Ghana Statistical Service. Ghana Multiple Indicator Cluster Survey with an Enhanced Malaria Module and Biomarker, Final report. Accra Ghana. 2011.

\section{Citation:}

Opoku BK and Nguah SB. Utilization of the modified WHO partograph in assessing the progress of labour in a metropolitan area in Ghana. Res J of Womens Health. 2015; 2:2.

http://dx.doi.org/10.7243/2054-9865-2-2 